\title{
ARSPIVOT, A SENSOR-BASED DECISION SUPPORT SOFTWARE FOR VARIABLE-RATE IRRIGATION CENTER PIVOT Systems: PART A. DEVELOPMENT
}

\author{
M. A. Andrade, S. A. O’Shaughnessy, S. R. Evett
}

Beyond 2020,

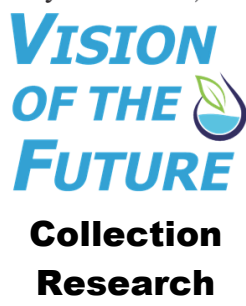

\section{HighLights}

- The ARSPivot software seamlessly integrates site-specific irrigation scheduling methods with weather, plant, and soil water sensing systems in the operation of variable-rate irrigation (VRI) center pivot systems.

- ARSPivot embodies an Irrigation Scheduling Supervisory Control and Data Acquisition (ISSCADA) system that incorporates site-specific irrigation scheduling methods and automates the collection and processing of data obtained from sensing systems supporting them.

- ARSPivot incorporates a friendly graphical user interface (GUI) that assists in the process of setting up a computerized representation of a coupled ISSCADA VRI center pivot system and simplifies the review of irrigation prescriptions automatically generated based on sensor feedback.

- ARSPivot's GUI includes a geographic information system (GIS) that relates sensed data and imported GIS data to specific field control zones.

ABSTRACT. The commercial availability of variable-rate irrigation (VRI) systems gives farmers access to unprecedented control of the irrigation water applied to their fields. To take full advantage of these systems, their operations must integrate sitespecific irrigation scheduling methods that in turn should be supported by a network of sensing systems. An Irrigation Scheduling Supervisory Control and Data Acquisition (ISSCADA) system patented by scientists with the USDA-Agricultural Research Service (ARS) at Bushland, Texas, incorporates site-specific irrigation scheduling methods informed by weather, plant, and soil water sensing systems. This article introduces a software package, ARSPivot, developed to integrate the ISSCADA system into the operation of VRI center pivot systems. ARSPivot assists the operation and integration of a complex network of sensing systems, irrigation scheduling methods, and irrigation machinery to achieve this end. ARSPivot consists of two independent programs interacting through a client-server architecture. The client program is focused on automatically collecting and processing georeferenced data from sensing systems and communicating with a center pivot control panel, while the server program is focused on communicating with users through a friendly graphical user interface (GUI) involving a geographic information system (GIS). The GUI allows users to visualize and modify site-specific prescription maps automatically generated based on sensor-based irrigation scheduling methods, and to control and monitor the application of irrigation amounts specified in these recommended prescription maps using center pivots equipped for VRI zone control or VRI speed control. This article discusses the principles and design considerations followed in the development of ARSPivot and presents tools implemented in the software for the virtual design and physical operation of a coupled ISSCADA VRI center pivot system. This article also illustrates how the ISSCADA system and ARSPivot constitute a comprehensive sensor-based decision support system (DSS) for VRI management that is accessible to users without in-depth knowledge of sensing systems or irrigation scheduling methods.

cC)() $\Theta$ The authors have paid for open access for this article. This NonCommercial-NoDerivatives 4.0 International License https://creative commons.org/licenses/by-nc-nd/4.0/

Submitted for review in January 2020 as manuscript number NRES 13907; approved for publication as a Research Article and as part of the National Irrigation Symposium 2020 Collection by the Natural Resources \& Environmental Systems Community of ASABE in May 2020.

Mention of company or trade names is for description only and does not imply endorsement by the USDA. The USDA is an equal opportunity provider and employer.

The authors are Manuel A. Andrade, Assistant Professor, Department of Agriculture, Veterinary, and Rangeland Science, University of Nevada, Reno, Nevada; Susan A. O'Shaughnessy, Research Agricultural Engineer, and Steven R. Evett, Research Soil Scientist, USDA-ARS Conservation and Production Research Laboratory, Bushland, Texas. Corresponding author: Susan A. O'Shaughnessy, P.O. Drawer 10, Bushland, TX $79012-$ 0010; phone: 806-356-5770; e-mail: susan.oshaughnessy@usda.gov.
Keywords. Center pivot irrigation, Decision support system, Precision agriculture, Sensors, Site-specific irrigation scheduling, Software, Variable rate irrigation.

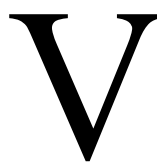
ariable-rate irrigation (VRI) technology offers potential economic and environmental benefits resulting from better control of water applied to a field (Evans et al., 2013). For these benefits to materialize, farmer-accessible irrigation scheduling methods must be embedded into the operation of VRI systems so that farmers can easily determine when and how much water to apply to different parts of a field. The methods must be capable of accounting for differences in crop water needs caused by variability within the field (e.g., due to topography, plant density, soil properties, etc.) and over the season 
(e.g., due to spatial variations in plant development and weather). Such site-specific irrigation scheduling methods in turn must be supported by a network of sensing systems, whose type, number, and spatial arrangement of nodes ensure a sufficiently accurate estimation of plant water requirements to meet the management objectives established for each irrigation management zone in a field. It is impractical to manually operate the complex network of sensing systems, irrigation scheduling methods, and irrigation machinery involved because that would be a time-consuming task requiring highly skilled labor.

Efficient operation of such a complex network requires the assistance of a decision support system (DSS) that integrates the management of its multiple components, automates the collection of data from its sensing systems and the application of algorithms to transform those data into sitespecific irrigation prescription maps, and incorporates a graphical user interface (GUI) through which those maps can be easily analyzed, modified, and put into action by the irrigation manager. Packaging the producer interface in a userfriendly and easy-to-implement fashion is a big challenge for the commercialization of site-specific irrigation (King et al., 2005). The GUI of such a DSS should thus also integrate tools that assist users in capturing all relevant data input parameters (i.e., information on fields, crops, sensing systems, and irrigation machinery) to facilitate user adoption. Kranz et al. (2012) noted that a successful DSS for site-specific irrigation management should be provided with user-friendly data input capabilities that allow prescription maps to be adjusted frequently during the growing season. Hence, a DSS for site-specific irrigation management must simplify the process of reviewing irrigation decisions based on sensor feedback.

Multiple efforts have been made toward the development of DSS for assisting irrigation management. Most of these efforts have focused on conventional irrigation practices that estimate crop water requirements of individual fields that are assumed to have uniform properties (Andales et al., 2014; Leib et al., 2001; Navarro-Hellín et al., 2016; Oswald, 2006; Prajamwong et al., 1997; Singels et al., 1998; Thysen and Detlefsen, 2006). A few DSS have been developed that are capable of accounting for non-uniform conditions in a field. These DSS quantify the variability of crop water needs within fields using multiple soil water sensors (Evans et al., 2012; King et al., 2005; Liakos et al., 2017). Other DSS use multiple plant sensors (O'Shaughnessy and Evett, 2010; O'Shaughnessy et al., 2012, 2013, 2015, 2017; Peters and Evett, 2008) in addition to microclimate data. However, the DSS designed to account for variable conditions in a field have lacked either a GUI to assist in the operation of the DSS (King et al., 2005) or graphical tools to assist in the capture of data and the visualization and modification of site-specific prescription maps, or required third-party software for this purpose (Liakos et al., 2017).

This article introduces the ARSPivot software package developed as an embodiment of the Irrigation Scheduling Supervisory Control and Data Acquisition (ISSCADA) system (Evett et al., 2014) patented by scientists at the USDAARS Conservation and Production Research Laboratory (CPRL). The ISSCADA system provides a framework for comprehensive irrigation management of crops using center pivot and lateral move irrigation systems and site-specific irrigation scheduling methods supported by an automated network of plant, soil, and weather sensing systems. The ISSCADA system was the result of experience accumulated over multiple studies conducted at the CPRL in Bushland, Texas, using VRI center pivots and irrigation scheduling methods based on plant stress (O'Shaughnessy and Evett, 2010; O'Shaughnessy et al., 2012, 2013, 2015, 2017; Peters and Evett, 2008). These studies demonstrated that a DSS using plant feedback could be used to intensely manage irrigated crop production with little labor, while still obtaining yield and crop water productivity (yield per unit of water consumed) values comparable to those obtained using laborintensive neutron probe (NP) measurements. The former method was often better than those obtained using best local management practices. Evett et al. (2020) described the development of the ISSCADA system and supporting wireless sensor subsystems.

ARS researchers at Bushland created an earlier software program to conduct these studies. The software integrated functions to support irrigation management by interfacing with weather and plant sensing systems and by implementing plant stress-based irrigation scheduling methods to generate site-specific prescription maps. The software was written in the Visual Basic programming language and incorporated functions to submit prescription maps to irrigation system control panels (Pro2, Valmont Industries, Valley, Neb.) managing the operation of a three-span and a six-span center pivot equipped for VRI zone control. A simple GUI implemented in the software displayed basic information regarding the status of the center pivots and allowed their operation through the submission of commands to their control panels (Andrade et al., 2015; O'Shaughnessy et al., 2015, 2017). However, the GUI lacked the means to display prescription maps (or to facilitate their modification) and tools to assist in entering input parameters for management setups, such as the dimensions of a center pivot, number of sprinkler zones, perimeters of management zones, crop and irrigation treatment of each zone, etc. Consequently, there were two versions of the earlier software, one to manage the three-span VRI center pivot and the other to manage the six-span VRI center pivot, and both versions had to be modified before the start of each growing season to fit the requirements of new management setups. Nevertheless, this earlier software was used as a basis for the creation of the ARSPivot software because it contained valuable computer code tested over multiple growing seasons.

The main objectives of ARSPivot are to allow seamless integration of the ISSCADA system into the operation of VRI center pivots and to help its users make better-informed decisions regarding irrigation management by means of a set of tools developed for the spatial and temporal analysis of data collected by the sensing systems supporting the ISSCADA system. This article describes the development of ARSPivot and presents the main tools implemented in the software to meet the first objective, beyond those discussed by Andrade et al. $(2015,2017)$. An accompanying article by Andrade et al. (2020) shows how the software was used for the integrated irrigation management of a VRI center pivot 
system during two growing seasons and illustrates the use of the geospatial data analysis tools implemented in ARSPivot to meet the second objective.

\section{Methodology}

ARSPivot is a software package that consists of two stand-alone programs interacting through a client-server architecture. Improvements made to the earlier software gave origin to the client program, and development of the GUI gave origin to the server program. The client is focused on establishing communication between ARSPivot, a network of weather, plant, and soil sensing systems, and a Pro2 control panel controlling a VRI center pivot irrigation system. The server was developed from the ground up and is focused on establishing communication between ARSPivot and its users and on providing users with multiple GUI/GIS based tools to assist in the configuration and operation of a coupled ISSCADA VRI center pivot system.

\section{Client Program}

The development of the client started with the generalization of case-specific functions in the earlier software so that these functions could be used in a wide range of conditions without having to make code changes. Parallel to the code generalization, new functions were developed to allow the operation of center pivots equipped only for VRI speed control, to interface with soil water sensing systems, and to enable users to choose the source of local weather data from either a standalone weather station (Campbell Scientific, Logan, Utah), a cloud service (e.g., AgSense, 2019) storing the information collected by a weather station (Davis Instruments, Hayward, Cal.), or an agrometeorological website (e.g., http://agebb.missouri.edu/). The client automates the collection and processing of data obtained from weather, plant, and soil water sensing systems supporting two sitespecific irrigation scheduling methods incorporated by the ARSPivot software: an integrated crop water stress index (iCWSI) algorithm already implemented in the earlier software, and a hybrid method that combines soil water data with the iCWSI algorithm. Both methods are described in detail in the following text.

The plant sensing required by these methods employs a network of infrared thermometers (IRTs) (SapIP-IRT, Dynamax, Houston, Tex.; Colaizzi et al., 2018; O'Shaughnessy et al., 2011) positioned at stationary locations within the field and mounted along the center pivot lateral (fig. 1). The IRTs mounted on the center pivot lateral are located forward of water applicators (spray sprinklers or drop hoses) and view the crop at an oblique angle between horizontal and nadir. The IRTs are arranged in pairs at the borders of a sprinkler zone (typically multiple water applicators controlled as an ensemble) and oriented with opposite views of the same area in the field in order to reduce sun angle effects on the mean zone temperature. The wireless soil water sensing network consists of multiple soil water sensing stations located within the field. The stations are comprised of dataloggers with internal radios (e.g., CR206x, Campbell Scientific) that communicate with a base radio connected to the embedded computer, and time domain reflectometry (TDR) sensors (TDR-315x, Acclima, Meridian, Ida.; Schwartz et al., 2016) installed at different depths (fig. 1). Local weather data (air temperature, precipitation, relative humidity, solar irradiance, wind speed, and wind direction) are averaged and stored every $1 \mathrm{~min}$ for the standalone weather station or every $5 \mathrm{~min}$ for the cloud storage service and the agrometeorological website (fig. 1). The first two steps involved in the generation of a site-specific prescription map with the ARSPivot software require the client to automatically gather and process the sensing data collected by the weather station

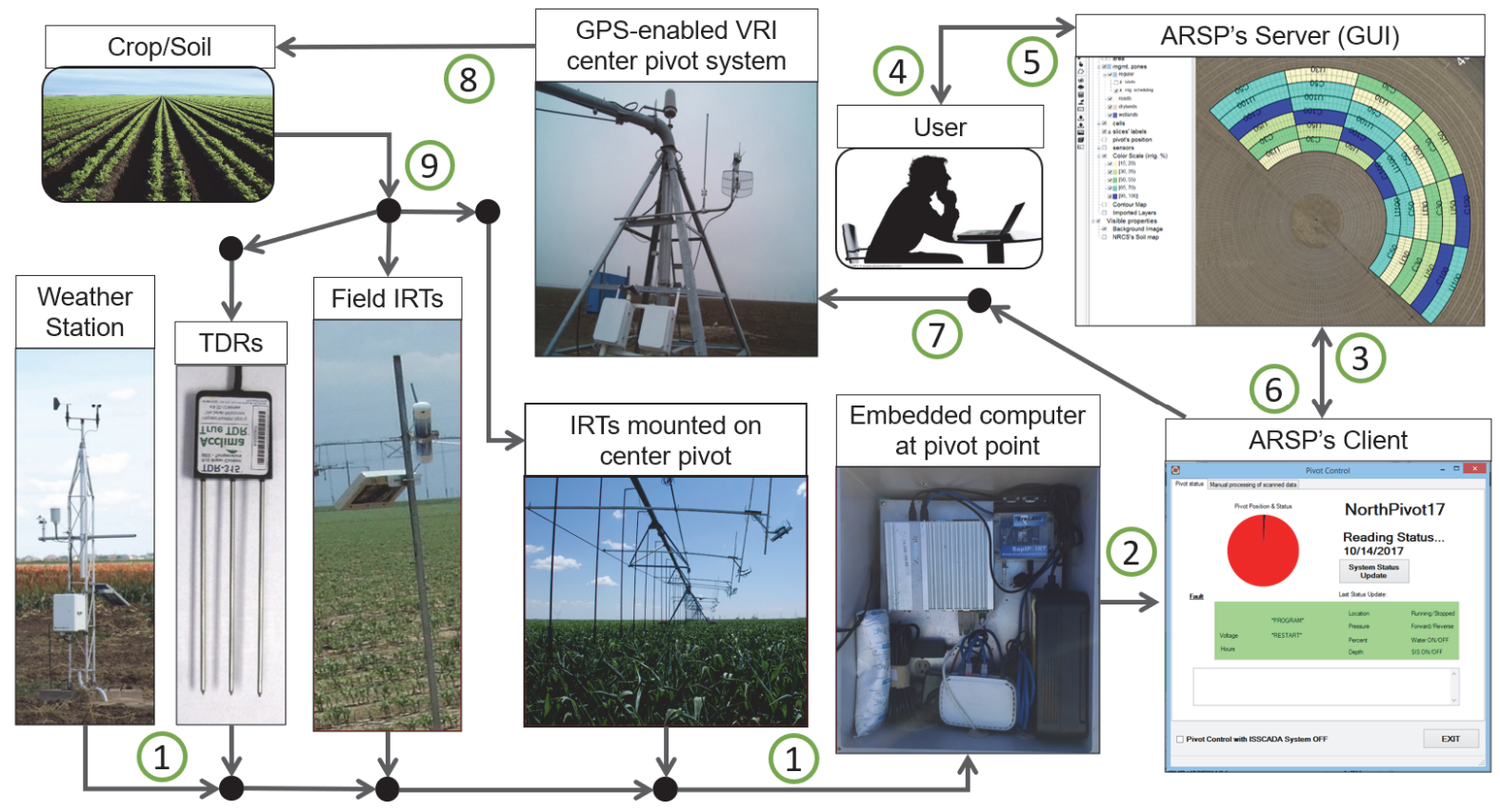

Figure 1. Interaction of the ARSPivot software package with its user, a network of plant, weather, and soil water sensing systems, and a VRI center pivot system operated with a Pro2 control panel for the generation and application of site-specific prescription maps. The process occurs through nine stages noted by circled numbers. 

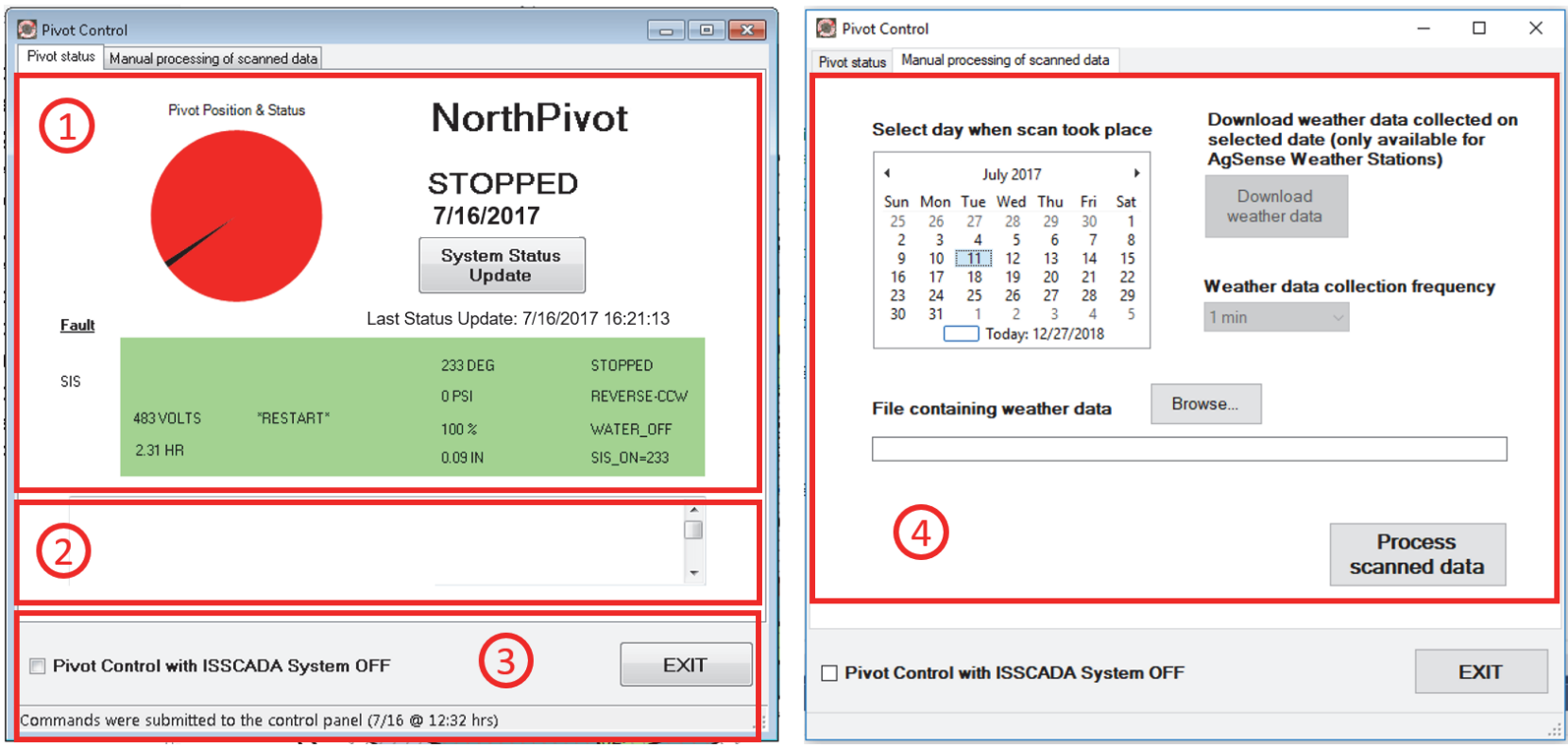

Figure 2. Simple GUI of client program consisting of two tabs. The first tab (left) contains: (1) multiple indicators of center pivot status, (2) a window displaying details of the communication status between the client and the Pro2 panel, and (3) a checkbox that, when checked, disables the control of the center pivot using the ARSPivot software, and an exit button that closes the client. The second tab (right) contains (4) a "Process scanned data" button that triggers the processing of data collected by the sensing systems during the date selected in a calendar.

and by the wireless network of IRTs and TDRs (fig. 1). The rest of the steps are described later.

The client incorporates a simple GUI with two tabs: one simulates the screen of a Pro2 panel, displaying multiple indicators of the center pivot status (location, application depth, percent speed, etc.), and the other allows users to manually trigger the processing of data collected by sensing systems from a given date selected in a calendar (fig. 2). The second tab is useful in cases when the client cannot process such data automatically due to an error, such as missing information from any of the sensing systems.

\section{Server Program}

The server was developed as a geographic information system (GIS) following object-oriented programming principles supported by the C\# language. Five types of computational objects lie at the core of the server: cell, canopy temperature sensor, soil water sensor, management zone (MZ), and pivot. Cell objects represent the smallest zones within which irrigation amounts can be controlled with reasonable accuracy with the VRI center pivot; they are the basic components used to discretize areas irrigated by the VRI center pivot. For center pivots using VRI zone control, the cells have a trapezoidal shape delimited by the inner and outer perimeters of a sprinkler zone and by two lines converging at the center pivot point separated by an angle of $2^{\circ}$ (fig. 3 ). For center pivots using VRI speed control, the cells are sectors having a pie-slice shape delimited by the center pivot's perimeter, by an inner circular boundary if there is unirrigated area around the pivot point, and by two lines converging at the pivot point separated by an angle of $2^{\circ}$. Canopy temperature sensor and soil water sensor objects represent IRT and TDR sensors, respectively.

An MZ object represents an irrigation management zone, defined as an area of the field receiving the same irrigation management during a growing season. An MZ consists of a group of cells of any number, which are not required to be contiguous. By giving this flexibility to an $\mathrm{MZ}$ object, the server allows the assignment of a common irrigation management objective to multiple areas in the field. An MZ can be designated as a special MZ with no irrigation (e.g., road, rock pile, pond, waterway, or dryland) or with an irrigation that is always set to a maximum depth, or as an ordinary MZ with an irrigation that can vary during the growing season according to sensor feedback. An MZ also can be changed from an ordinary status to a special status at any time, which can be useful when it is no longer economically viable to continue irrigating the MZ. The server incorporates a set of tools, described below, that help users to delineate the areas of MZs, but it does not include a tool to delineate MZs automatically. MZs can be delineated following the boundaries of areas requiring any reasonable differentiation of irrigation management objectives, such as differences in soil properties or topography, or areas planted to different crops, planted at different densities, or at different dates. A pivot object represents a VRI center pivot irrigation system and the area it irrigates. A pivot object also stores lists of all the cells, canopy temperature sensors, soil water sensors, and MZs located inside the area represented by the pivot object.

The server incorporates GIS tools that allow the spatial representation and analysis of data relevant to the operation of an ISSCADA VRI center pivot system using geo-referenced maps displayed in its main panel. Each of the five types of computational objects is displayed in the main panel using either a scaled representation of its area (for pivot, cell, and $\mathrm{MZ}$ objects) (fig. 3) or a geometric shape (for canopy temperature and soil water sensor objects). In the latter case, small circles and triangles are used to represent IRTs located in the field and mounted on the center pivot, respectively, 


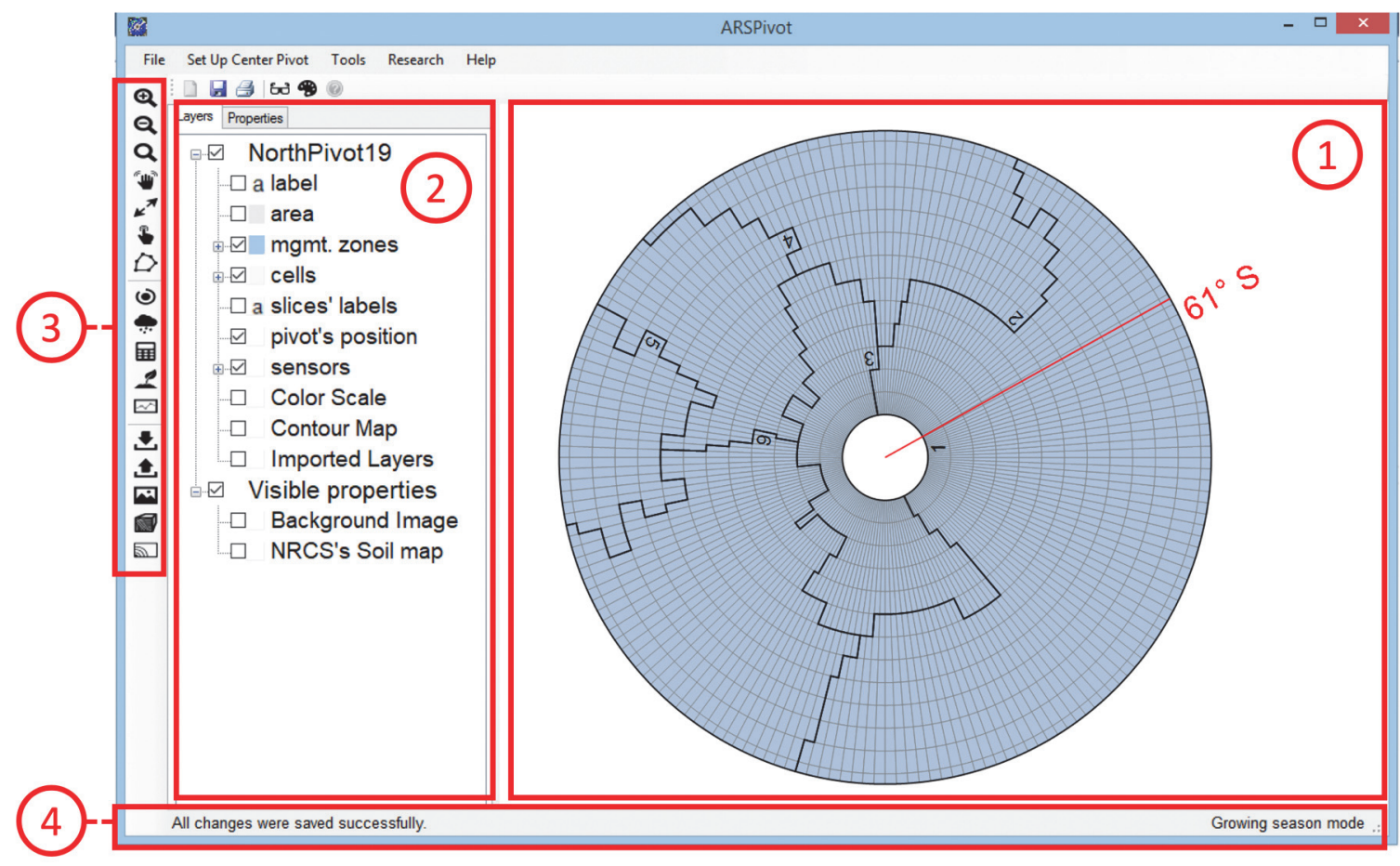

Figure 3. Main screen of server. (1) The main panel shows a scaled representation of the area irrigated by a center pivot equipped for VRI zone control with 12 sprinkler zones. Six management zones (MZs) were created by grouping six sets of cells. The radial line extending from the center of the field indicates the position of the center pivot. (2) The side panel contains a tree view with a list of layers available for display in the main panel. (3) The toolbar contains icons for basic GIS tools (zoom in, zoom out, etc.), water management tools (build a prescription map, start an irrigation, monitor the center pivot's status, etc.), and advanced tools (display a background satellite image, obtain a soil contour map, etc.). (4) The status bar provides feedback to users regarding the status of actions they trigger.

and small squares are used to represent TDR soil water sensing stations. All items drawn in the server's main panel are georeferenced using Universal Transverse Mercator (UTM) projection and are arranged in layers that users can show or hide by checking or unchecking boxes in a tree view displayed in a side panel next to the main panel (fig. 3). After a user enters basic information for a specific center pivot through the pivot builder form (fig. 4), such as the latitude and longitude of its center point, the length of its radius, etc., the server generates a scaled representation of the center pivot field by performing an automatic conversion to UTM coordinates using formulas provided by Hager et al. (1989) and the WGS84 datum. Properties of the computational objects can be visualized and modified through tables displayed after a user selects an object by clicking any point inside the area or shape representing the object. Tables of the object properties are displayed in a side panel in the GUI instead of the tree view containing the list of layers (fig. 3). If multiple objects of the same type are selected, a table containing common properties of all selected objects will be displayed.

\section{Client-Server InTERACTION}

The client and server programs run simultaneously on an embedded computer connected to the control panel of the VRI center pivot system with an RS232 cable (fig. 1). A Microsoft Windows operating system (version 7.0 or later) is required for the embedded computer, and internet access is recommended so that ARSPivot can be operated remotely by a desktop PC or mobile device using remote support software, such as Microsoft Remote Desktop (Microsoft, 2019). Figure 1 also illustrates the interaction of the client and server with a user, the described network of sensing systems, and a VRI center pivot system operated with a Pro2 control panel for the generation and application of site-specific prescription maps. The process occurs through the following steps, all of which are automated except for the user input in steps 5 and 6 :

1. The client collects time-stamped data from a weather station, the wireless network of IRTs mounted on the moving center pivot lateral, and the wireless networks of IRTs and TDRs stationed in the field, and it uses position data from the center pivot to georeference the data collected from moving sensors.

2. The georeferenced and time-stamped data are stored in the embedded computer running the ARSPivot software and are processed by the client around midnight.

3. The processed data are sent to the server, which uses the iCWSI method or the hybrid method to determine the irrigation amount to be applied to each $\mathrm{MZ}$ in the field.

4. The resulting site-specific prescription map is presented in a friendly format to the user through the GUI implemented in the server.

5. The user inspects the prescription map and, if needed, modifies it.

6. The user sends the prescription to the client via the server.

7. The client submits the prescription to the Pro2 panel.

8. The Pro2 panel manages the application of the prescription by the VRI center pivot. 


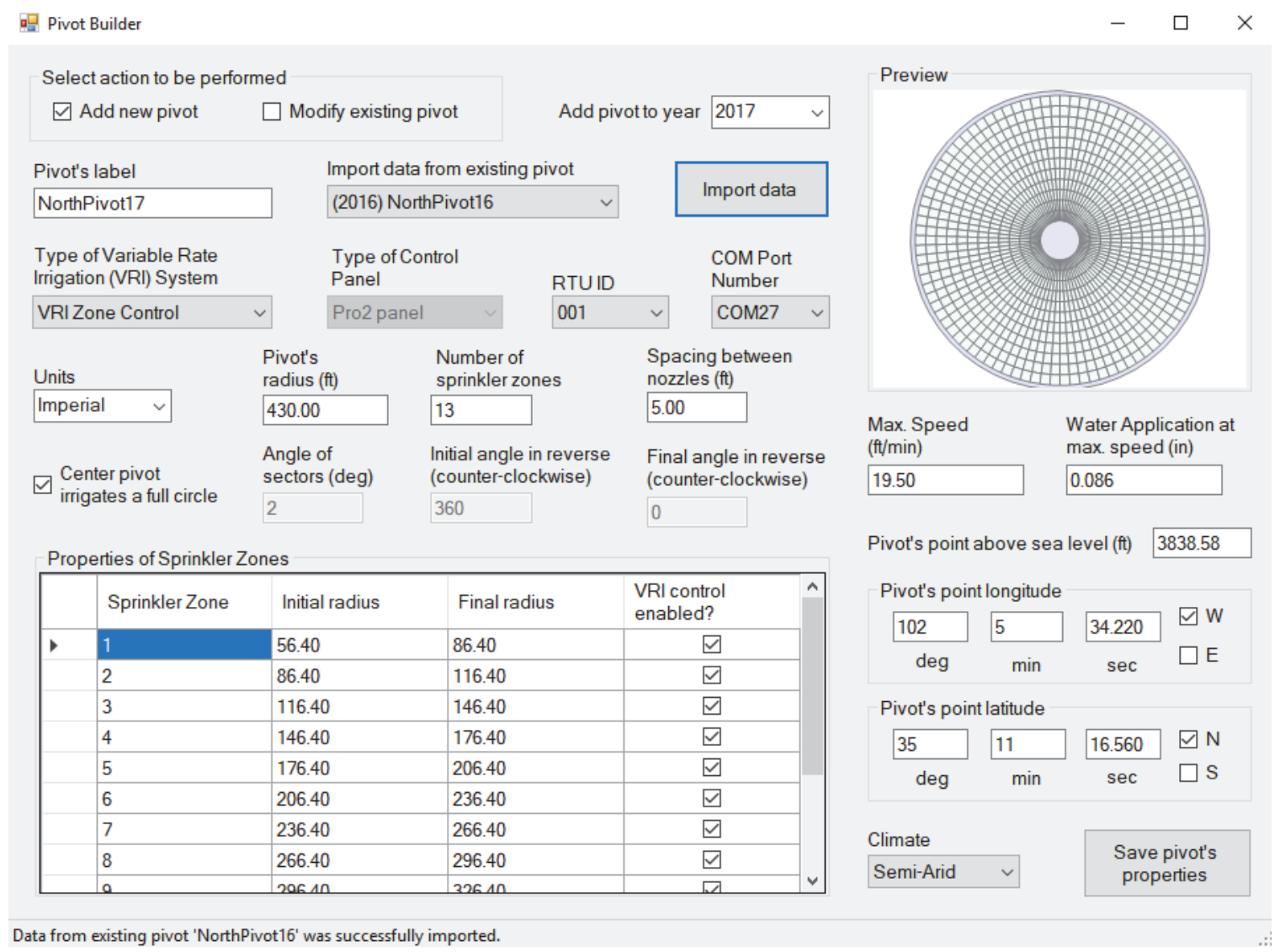

Figure 4. Pivot builder form used to enter the basic information of new VRI center pivot systems. The window in the top right corner displays a preview of the grid of cells that will be used as a basis for the MZs. The preview is updated automatically as the user modifies the information in the form. Values are in customary units for U.S. end users, but the server also supports the use of SI units.

9. The process starts again after (or even during) the irrigation with the collection (step 1) of a new set of canopy temperature, soil water content, and weather data.

Maintaining the client and server as separate programs improves the reliability of ARSPivot because it prevents any potential problem caused by one program from affecting the other. In particular, communication issues experienced when remotely interacting with the server program do not affect the separately running client program. Reliability is a particularly important feature for the client because this program has been entrusted with maintaining continuous communication with the sensing systems and the Pro2 control panel. Hence, the client contains a minimum set of functions required to establish such communication and to remain in alert mode, waiting to receive instructions from the user through the server, which implements all other functions required for the site-specific irrigation management of ISSCADA center pivots.

The server program was developed to be capable of operating multiple ISSCADA-VRI center pivot systems remotely and displaying computerized representations of these systems simultaneously in the main screen of its GUI. This feature required a robust and secure communication protocol between the desktop PC running the server program at a central location and multiple embedded computers, each running a client program for a field irrigated with a VRI center pivot irrigation system. A communication protocol based on the use of network sockets (Microsoft, 2020) was tested in earlier versions of ARSPivot, but its implementation resulted in erratic communication between the server and the clients. This protocol was thus replaced in later versions of ARSPivot with a simpler and more robust protocol that requires the server and client to be running on the same computer. The new protocol ensures continuous communication between the server and client at the cost of preventing simultaneous operation of multiple ISSCADA-VRI center pivot systems using the server.

\section{IRRIGATION SCHEDULING METHODS}

The code within the server supports three irrigation scheduling methods: an iCWSI method, a hybrid method, and a manual method in which users are responsible for prescribing irrigation amounts. The server gives users the flexibility of selecting up to three irrigation levels as defined by the percentage replenishment of soil water depletion to field capacity or by the equivalent thresholds of the IRT-sensed crop water stress, or the combination of sensed crop water stress and soil water depletion for the ISSCADA iCWSI and hybrid methods, respectively. Farmers often need a single treatment that may match full replenishment. Although these treatment options are mostly used by researchers interested in comparing varying degrees of soil water depletion, a farmer may choose to apply different irrigation treatments to different crops planted under one center pivot. The server also allows users to select up to three irrigation amounts 
(minimum, medium, and maximum) per treatment selected for the iCWSI and hybrid methods (fig. 5).

The iCWSI irrigation scheduling method is based on calculating the sum of theoretical CWSI (Jackson et al., 1981) values obtained at discrete time intervals during daylight hours:

$$
\operatorname{iCWSI}_{x}=\sum_{t=1}^{n}\left[\frac{\left(T_{c}-T_{a}\right)-\left(T_{c}-T_{a}\right)_{l l}}{\left(T_{c}-T_{a}\right)_{u l}-\left(T_{c}-T_{a}\right)_{l l}}\right]
$$

where $\mathrm{iCWSI}_{x}$ is the $\mathrm{iCWSI}$ calculated at any given location $x$ in a field, $T_{c}$ is the canopy temperature at location $x$ at time $t$ estimated using the canopy temperature scaling algorithm reported by Peters and Evett (2004), $T_{a}$ is the air temperature at time $t,\left(T_{c}-T_{a}\right)_{l l}$ is the lower limit of the difference between $T_{c}$ and $T_{a}$ occurring for a well-watered crop, $\left(T_{c}-T_{a}\right)_{u l}$ is the upper limit of the same difference occurring for a severely stressed crop, and $n$ is the total number of time intervals used to discretize daylight hours. Equations used to calculate the lower and upper limits of the difference between $T_{c}$ and $T_{a}$ were provided by O'Shaughnessy et al. (2012). The algorithm reported by Peters and Evett (2004) scales a onetime-of-day canopy temperature measurement obtained from mobile IRTs against a reference temperature curve obtained from static IRTs to estimate the canopy temperature $\left(T_{c}\right)$ at any given location and time during daylight hours (from $2 \mathrm{~h}$ after sunrise to $2 \mathrm{~h}$ before sunset). The iCWSI method cannot be used as a real-time irrigation scheduling method because the estimation of $\mathrm{iCWSI}_{x}$ values with equation 1 requires the collection of canopy temperature and weather sensing data over the daylight hours for a $24 \mathrm{~h}$ period.

Irrigation scheduling of an MZ using the iCWSI method is determined by comparing all the $\mathrm{iCWSI}_{x}$ values computed inside the $\mathrm{MZ}$ against a set of pre-established plant stress thresholds that are dependent on the crop, region, and irrigation management objectives established for the MZ. The number of thresholds in this set is equal to the number of irrigation depths that can be used per irrigation treatment (fig. 5). When only one threshold $\left(L_{\text {thresh }}\right)$ and one irrigation amount $(D)$ are used, the irrigation depth $\left(D_{\mathrm{MZ}}\right)$ scheduled for an $\mathrm{MZ}$ is equal to $D$ if at least half of the $\mathrm{iCWSI}_{x}$ values computed inside the $\mathrm{MZ}$ are greater than or equal to the threshold. No irrigation is scheduled for the $\mathrm{MZ}$ otherwise. This can be formally represented by equation 2 :

$$
D_{\mathrm{MZ}}= \begin{cases}0 & \text { if } n_{\text {min }}>n_{\max } \\ D & \text { if } n_{\text {min }} \leq n_{\max }\end{cases}
$$

where $n_{\min }$ is the total number of $\mathrm{iCWSI}_{x}$ values computed inside the $\mathrm{MZ}$ such that $\mathrm{iCWSI}_{x}<L_{\text {thresh }}$, and $n_{\max }$ is the total number of $\mathrm{iCWSI}_{x}$ values computed inside the MZ such that $\mathrm{iCWSI}_{x} \geq L_{\text {thresh }}$. When two thresholds ( $L_{\text {thresh_min }}$ and $\left.L_{\text {thresh_max }}\right)$ and two irrigation amounts $\left(D_{\min }\right.$ and $\left.\bar{D}_{\max }\right)$ are

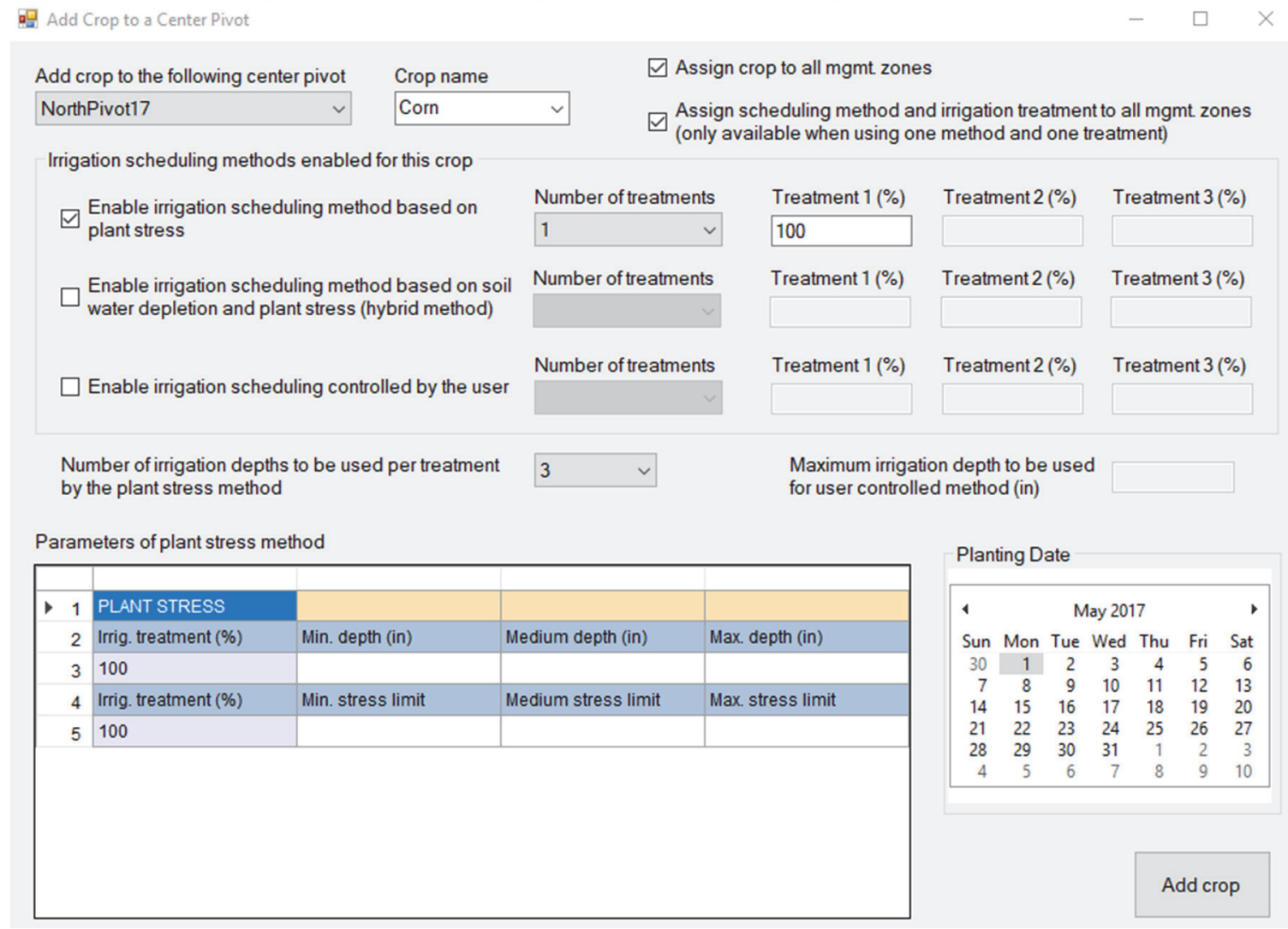

Figure 5. Crop builder form used to enter information on crops and scheduling methods to be used in irrigation management. Users can enable an iCWSI method based on plant stress, a hybrid method based on the estimation of an average soil water depletion in the root zone and on plant stress, and a manual method in which users prescribe irrigation amounts. Users can select up to three irrigation treatments (levels of replenishment of soil water depletion) and up to three irrigation depths (minimum, medium, and maximum) for each treatment. Values are in customary units for U.S. end users. 
used, the irrigation depth $\left(D_{\mathrm{MZ}}\right)$ scheduled for an MZ by the iCWSI method is determined by equation 3 :

$$
D_{\mathrm{MZ}}=\left\{\begin{array}{cl}
0 & \text { if } n_{\text {min }}>n_{\text {med }} \text { and } n_{\text {min }}>n_{\text {max }} \\
D_{\text {min }} & \text { if } n_{\text {med }} \geq n_{\text {min }} \text { and } n_{\text {med }}>n_{\text {max }} \\
D_{\text {max }} & \text { if } n_{\text {max }} \geq n_{\text {min }} \text { and } n_{\text {max }} \geq n_{\text {med }}
\end{array}\right.
$$

where $n_{\min }$ is the total number of $\mathrm{iCWSI}_{x}$ values computed inside the MZ such that iCWSI ${ }_{x}<L_{\text {thresh }}$ min,$n_{\text {med }}$ is the total number of $\mathrm{iCWSI}_{x}$ values computed inside the $\mathrm{MZ}$ such that $L_{\text {thresh_min }} \leq \mathrm{iCWSI}_{x}<L_{\text {thresh_max }}$, and $n_{\max }$ is the total number of $\mathrm{iCWSI}_{x}$ values computed inside the MZ such that $\mathrm{iCWSI}_{x}$ $\geq L_{\text {thresh_max }}$. An analogous formula is used to determine the irrigation depth $\left(D_{\mathrm{MZ}}\right)$ of an $\mathrm{MZ}$ with three thresholds ( $L_{\text {thresh_min }}, L_{\text {thresh_med, }}$ and $L_{\text {thresh_max }}$ ) and three irrigation amounts $\left(D_{\min }, D_{\text {med }}\right.$, and $\left.D_{\max }\right)$. An example of how the iCWSI method is used in such cases is presented in table 1 . No irrigation is applied to an $\mathrm{MZ}$ if $\mathrm{iCWSI}_{x} \leq 100$ for most iC$\mathrm{WSI}_{x}$ values in the MZ. A minimum depth $\left(D_{\min }\right)$ is applied to an $\mathrm{MZ}$ if $100<\mathrm{iCWSI}_{x} \leq 150$ for most $\mathrm{iCWSI}_{x}$ values in the MZ, a medium depth $\left(D_{\text {med }}\right)$ is applied to an MZ if $150<$ $\mathrm{iCWSI}_{x} \leq 250$ for most iCWSI values in the MZ, and a maximum depth $\left(D_{\max }\right)$ is applied to an MZ if $\mathrm{iCWSI}_{x}>250$ for most iCWSI $x$ values in the MZ. Details on selecting plant stress thresholds are provided by Andrade et al. (2020).

The hybrid irrigation scheduling method combines feedback data from soil water sensing stations with the iCWSI method to provide a feedback loop with the objectives of preventing under- and over-irrigation and adding redundancy to the irrigation scheduling framework of the ARSPivot software package (fig. 1). The redundancy offered by soil water sensing feedback is especially important in sub-humid and humid regions, where the ISSCADA system has been deployed (O'Shaughnessy et al., 2018; Stone et al., 2019; Vories et al., 2019), because the iCWSI method could be misleading in high-humidity conditions (Evett et al., 2020). The hybrid method uses a two-step approach to determine the irrigation amount to be prescribed to an MZ. During the first step, an average soil water depletion in the root zone (SWDr) is calculated from data collected by a set of TDR sensors buried at different depths at one location within the MZ (this assumes one soil water station per MZ) and then compared against pre-established minimum and maximum thresholds $\left(\mathrm{SWD} r_{\min }\right.$ and $\left.\mathrm{SWD} r_{\max }\right)$. The value of the minimum threshold is selected to prevent over-irrigation so that no irrigation is assigned for the $\mathrm{MZ}$ if the $\mathrm{SWD} r$ is less than $\mathrm{SWD} r_{\min }$. The value of the maximum threshold is selected to prevent under-irrigation so that a maximum irrigation amount $\left(D_{\max }\right)$ is assigned if the $\mathrm{SWD} r$ is greater than $\mathrm{SWD} r_{\text {max }}$. Otherwise, the iCWSI method is used during the second step to determine the prescription $\left(D_{\mathrm{MZ}}\right)$ scheduled for the MZ, as shown in equation 4:

$$
D_{\mathrm{MZ}}=\left\{\begin{array}{cc}
0 & \text { if } \mathrm{SWD} r<\mathrm{SWD} r_{\text {min }} \\
D_{\mathrm{iCWSI}} & \text { if } \mathrm{SWD} r_{\text {min }} \leq \mathrm{SWD} r \leq \mathrm{SWD} r_{\text {max }} \\
D_{\text {max }} & \text { if } \mathrm{SWD} r>\mathrm{SWD} r_{\text {max }}
\end{array}\right.
$$

where $D_{\text {iCwSI }}$ is the irrigation depth obtained with the iCWSI method for the MZ, and $D_{\max }$ is equal to the maximum irrigation amount used by the iCWSI method. Note that the irrigation depth $\left(D_{\text {iCwsI }}\right)$ will be determined with equations 2 or 3 when one or two plant stress thresholds (and irrigation amounts) are used by the iCWSI method, respectively. Additional details on selecting SWDr thresholds are provided by Andrade et al. (2020).

The average soil water depletion in the root zone (SWDr) is calculated as shown in equation 5:

$$
\mathrm{SWD} r=\frac{1}{\sum_{i=1}^{n} \mathrm{SI}_{i}}\left[\sum_{i=1}^{n}\left(\mathrm{SI}_{i} \times \frac{\mathrm{FC}_{i}-\mathrm{WC}_{i}}{\mathrm{FC}_{i}-\mathrm{WP}_{i}}\right)\right]
$$

where $n$ is the number of TDRs buried at a soil water sensing station located within the $\mathrm{MZ}, \mathrm{FC}_{i}$ and $\mathrm{WP}_{i}$ are the field capacity and wilting point water contents, respectively, at the depth where the $i$ th TDR is buried, $\mathrm{WC}_{i}$ is the volumetric water content measured by the $i$ th $\mathrm{TDR}$, and $\mathrm{SI}_{i}$ is the depth of the soil layer represented by the $i$ th TDR. The layer of influence $\left(\mathrm{SI}_{i}\right)$ of the $i$ th TDR is delimited by two horizontal planes: one crossing the midpoint between depths $\mathrm{PD}_{i-1}$ and $\mathrm{PD}_{i}$ at which the (i-1)th and $i$ th TDR probes are buried, respectively, and the other crossing the midpoint between depths $\mathrm{PD}_{i}$ and $\mathrm{PD}_{i+1}$, respectively. The depth of the layer for the $i$ th TDR is calculated with equation 6 :

$$
\mathrm{SI}_{i}=\frac{1}{2}\left(\mathrm{PD}_{i}+\mathrm{PD}_{i+1}\right)-\sum_{k=1}^{i-1} \mathrm{SI}_{k}
$$

where $\mathrm{PD}_{n+1}=2 \mathrm{PD}_{n}-\mathrm{PD}_{n-1}$ when $i=n$.

\section{Server Program Operation}

Basic information on the center pivot can be entered through the pivot builder form within the server program, where users indicate the type of VRI system (speed control or zone control), whether the center pivot irrigates a full circle (or otherwise the angles delimiting the area irrigated), its radius, geographic coordinates of its center, maximum speed and water applied at that speed, number of sprinkler zones, the inner and outer radii of each sprinkler zone (for VRI zone control), and other information (fig. 4). The pivot builder

\begin{tabular}{|c|c|c|c|c|}
\hline $\begin{array}{c}\text { Irrigation } \\
\text { Treatment Level } \\
(\%)\end{array}$ & $\begin{array}{c}\text { No Irrigation } \\
\operatorname{iCWSI}_{x} \leq 100\end{array}$ & $\begin{array}{c}\text { Minimum Depth } \\
\left(D_{\min }, \mathrm{mm}^{2}\right. \\
100<\mathrm{iCWSI}_{x} \leq 150\end{array}$ & $\begin{array}{c}\text { Medium Depth } \\
\left(D_{\text {med }}, \mathrm{mm}^{2}\right) \\
150<\mathrm{iCWSI}_{x} \leq 250\end{array}$ & $\begin{array}{l}\text { Maximum Depth } \\
\quad\left(D_{\max }, \mathrm{mm}\right) \\
\mathrm{iCWSI}_{x}>250\end{array}$ \\
\hline 80 & 0 & $15.2(0.6$ in. $)$ & 20.3 (0.8 in.) & 30.5 (1.2 in.) \\
\hline 50 & 0 & 10.3 (0.4 in.) & 12.7 (0.5 in.) & 19.1 (0.75 in.) \\
\hline 30 & 0 & 6.4 (0.25 in.) & 7.6 (0.3 in.) & $12.7(0.5$ in. $)$ \\
\hline
\end{tabular}

Table 1. Irrigation depths (mm) and iCWSI thresholds (dimensionless) used by Andrade et al. (2020) for site-specific irrigation management of corn with three irrigation depths (minimum, medium, and maximum) for each of three irrigation treatment levels, and the same iCWSI thresholds (100, 150, and 250) for all irrigation treatment levels. Details on selecting the iCWSI thresholds are provided by Andrade et al. (2020). 
form also allows users to modify the basic information of an existing center pivot or to import its information as a basis for the creation of a new center pivot. The support of speed control VRI can benefit many producers because this method of site-specific irrigation has a minimal learning curve, and most center pivot sprinkler systems presently sold are equipped for speed control VRI (O'Shaughnessy et al., 2019).

Once the basic information of a new VRI center pivot has been entered, the server generates a pivot computational object containing a scaled representation of the center pivot field that includes the cells used to discretize it. After the user closes the pivot builder form, this grid is displayed in the main panel, allowing the user to begin the process of delineating MZs by selecting cells to be grouped to create an MZ. Cells can be selected individually by clicking any point inside a cell or collectively by using a polygon selection tool that allows simultaneous selection of multiple cells inside a polygon drawn by the user. Additional tools for the delineation of MZs allow the user to overlay the grid of cells onto a satellite image of the center pivot field using Google Maps API (Google, 2019) (fig. 6) or onto a map of soil units obtained from the USDA-NRCS web soil survey API (USDANRCS, 2019). The user can also import a CSV file containing $X$ and $Y$ spatial coordinates and a $Z$ value to create a map of another variable that might be used to delineate MZs. For example, the $Z$ value could be bulk electrical conductivity data from field mapping accomplished using a Veris unit. Once cells are grouped into an MZ, the user can specify the $\mathrm{MZ}$ to be ordinary or of a special type (road, wetland, dryland, etc.).

The locations and basic information of plant and soil water sensing systems can be entered through canopy temperature sensing and soil water sensing data entry forms included in the server software. The locations of static IRTs are entered by specifying their geographic coordinates (longitude and latitude) or by clicking their positions in the main panel. The locations of mobile IRTs mounted on the center pivot are determined by their distances from the pivot point, which are entered into a table. Static IRTs are represented in the main panel by small circles that remain in place once specified. Mobile IRTs are represented by triangles located along the line representing the pivot pipeline, which moves as the pipeline moves (fig. 6). The interiors of these shapes are colored green if the most recent canopy temperature $\left(T_{c}\right)$ measured by the IRT is less than $35^{\circ} \mathrm{C}\left(95^{\circ} \mathrm{F}\right)$, red if $T_{c}$ is greater than $45^{\circ} \mathrm{C}\left(113^{\circ} \mathrm{F}\right)$, or yellow if $T_{c}$ is between these values. If no canopy temperature readings have been received from an IRT in the last $24 \mathrm{~h}$, the interior of the shape will become transparent, and its perimeter will be colored red; if the IRT

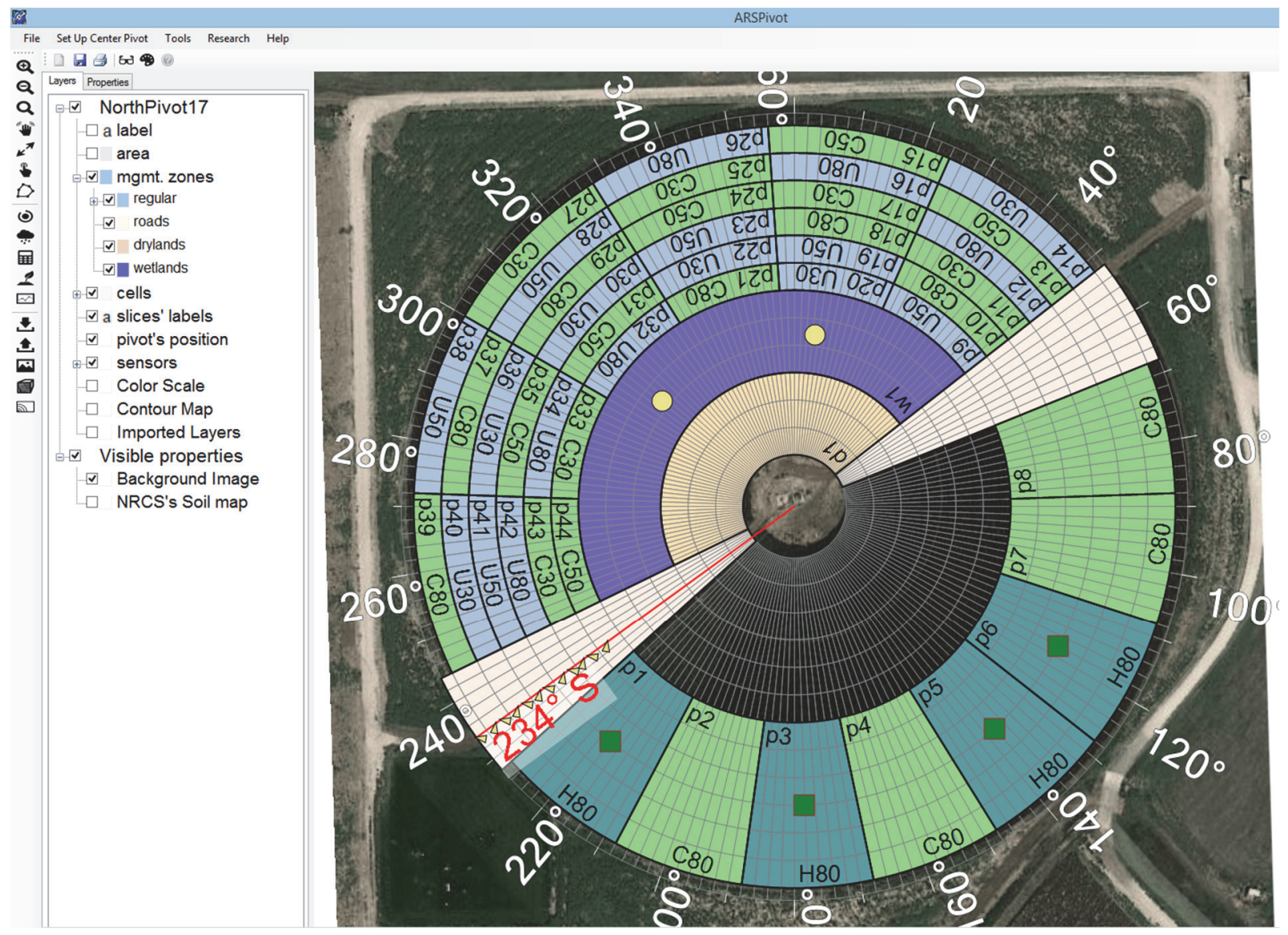

Figure 6. Experimental setup consisting of 44 plots irrigated with a three-span VRI center pivot irrigation system, as displayed in the GUI of the server. Letters $\mathrm{C}, \mathrm{H}$, and $\mathrm{U}$ inside the plots indicate that the scheduling method assigned to the plot is the iCWSI, hybrid, or manual method, respectively. Numbers 80,50 , and 30 (located next to letters $\mathrm{C}, \mathrm{H}$, or $\mathrm{U}$ ) correspond to the irrigation treatments assigned to the plots. Plots are identified by a number preceded by the letter $\mathrm{p}$. Squares inside plots in the south-southeast side using the hybrid method represent soil water sensing stations. Two circles inside a well irrigated area (noted as w1) represent static IRTs. Small triangles located along the line indicating the center pivot's position represent mobile IRTs mounted on the center pivot. 
is mobile, then the area of its triangle will be magnified to facilitate its identification in the main panel to indicate that the sensor or sensor system is malfunctioning. Similar to static IRTs, the locations of soil water sensing stations are entered by specifying their geographic coordinates or by clicking their positions in the main panel. The depth of each TDR sensor positioned in the soil water sensing station and the field capacity and wilting point at each depth are entered into a table. Soil water sensing stations are represented in the main panel by small squares with interior colors that change automatically to indicate the status of their average soil water depletion in the root zone (SWDr). Squares are colored green if SWDr is less than the minimum threshold SWD $r_{\text {min }}$ (fig. 5), red if SWDr is greater than the upper threshold $\mathrm{SWD} r_{\max }$, or yellow if the SWD $r$ value is between these limits. If no soil water content readings have been received from a soil water sensing station in the last $48 \mathrm{~h}$, the interior of the square representing the station will become transparent.

Also included in the server is a crop builder form that allows users to enter the crop type, planting date, the scheduling methods that will be enabled for its irrigation, and the parameters of each method (i.e., the plant stress thresholds and corresponding irrigation amounts used by the iCWSI method per treatment level, and the soil water depletion thresholds used by the hybrid method) (fig. 5). Depending on the sensing systems available, the user can choose the irrigation scheduling methods to be enabled. While producers will typically use one irrigation scheduling method, researchers may enable more than one method to investigate differences in yield and crop water productivities (Stone et al., 2019). Once the information for a crop has been entered, the user can assign this crop to all MZs by checking a box in the crop builder form (fig. 5). The server also allows users to enter the information for the management of more than one crop, which is useful for producers who diversify their crops within a single field, as well as for research studies. When more than one crop is entered, users are required to select the crop that will be irrigated inside each MZ. Only one crop can be assigned to an $M Z$ so that the entire area within the $M Z$ receives the same irrigation management.

Once the basic information for a new VRI center pivot and its MZs, crops, and sensing systems have been entered, the user can start the collection of data for the generation of recommended site-specific prescription maps by running the center pivot around the field. As the center pivot advances, the wireless network of IRTs mounted on the center pivot measures remote canopy temperatures, whose values and times of measurement are recorded so that each measurement can be georeferenced based on the geopositional records of the VRI center pivot system. Those spatial canopy temperature data and the data that are continuously collected by the wireless network of static IRTs and the weather station are processed by the client program around midnight to calculate average iCWSI values for all cells in the field where canopy temperatures were measured by mobile IRTs. After these values are calculated, the server uses them and the soil water content values measured by TDR sensors to trigger the automatic generation of a prescription map using the iCWSI and hybrid methods (fig. 7). The server generates a visual representation of the resulting prescription map that is displayed in the main panel so that users can inspect it remotely (fig. 7). Users can also trigger the generation of a prescription map manually using a prescription map builder form implemented in the server.

Figure 8 shows a recommended prescription map created as part of an experiment, described by Andrade et al. (2017), in which one portion of a field was irrigated using VRI zone control and another portion was irrigated using VRI speed (sector) control. The prescription map was generated one day after performing a scan of the field by running the center pivot dry across the field to measure remote canopy temperatures inside $44 \mathrm{MZs}$ (considered as experimental plots) using the wireless network of IRTs mounted on the center pivot. The areas of the MZs in figure 8 are colored according

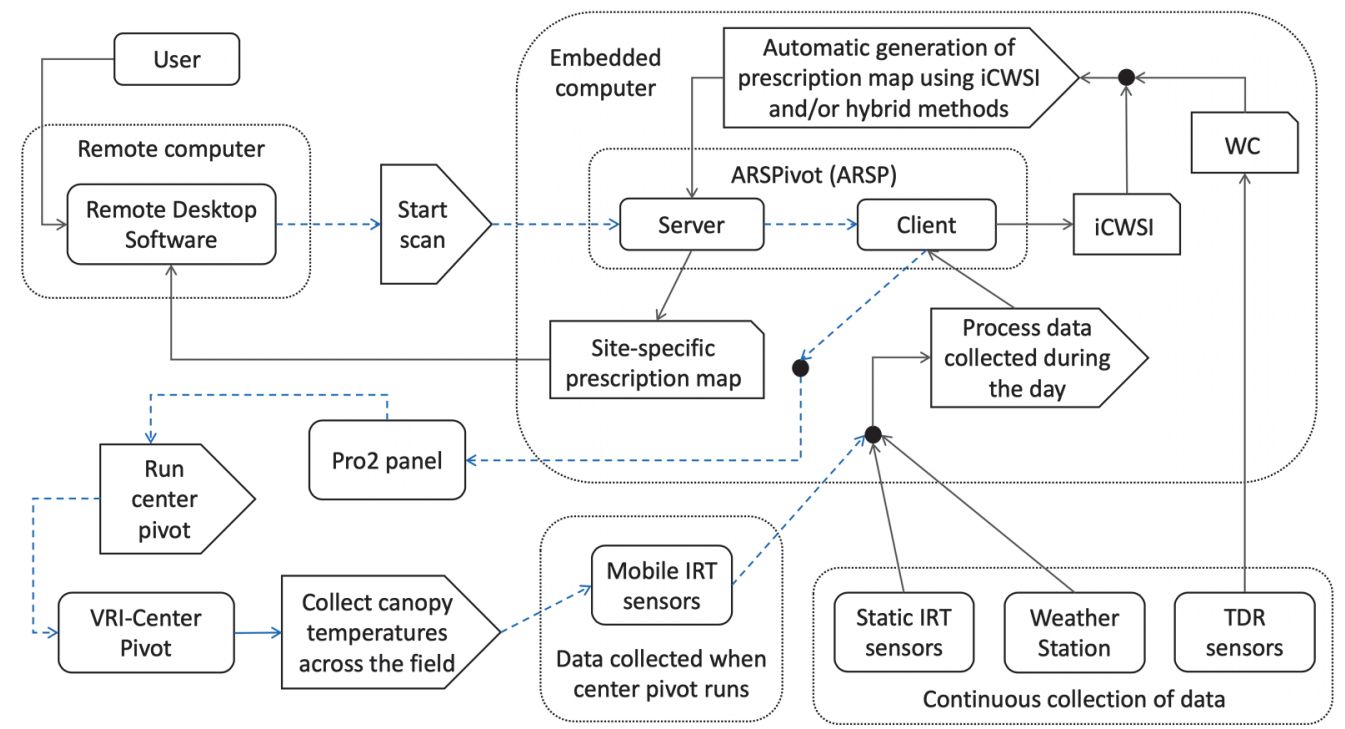

Figure 7. Flowchart showing the steps involved in automatic generation of a site-specific prescription map using ARSPivot. Blue dashed arrows connect steps required for the collection of canopy temperatures across the field. Black solid arrows connect steps required for the calculation of average iCWSI values for each cell in the field where canopy temperatures were measured, and steps required for the building of the prescription map using those iCWSI values and soil volumetric water content (WC) values measured by soil water sensing stations. 


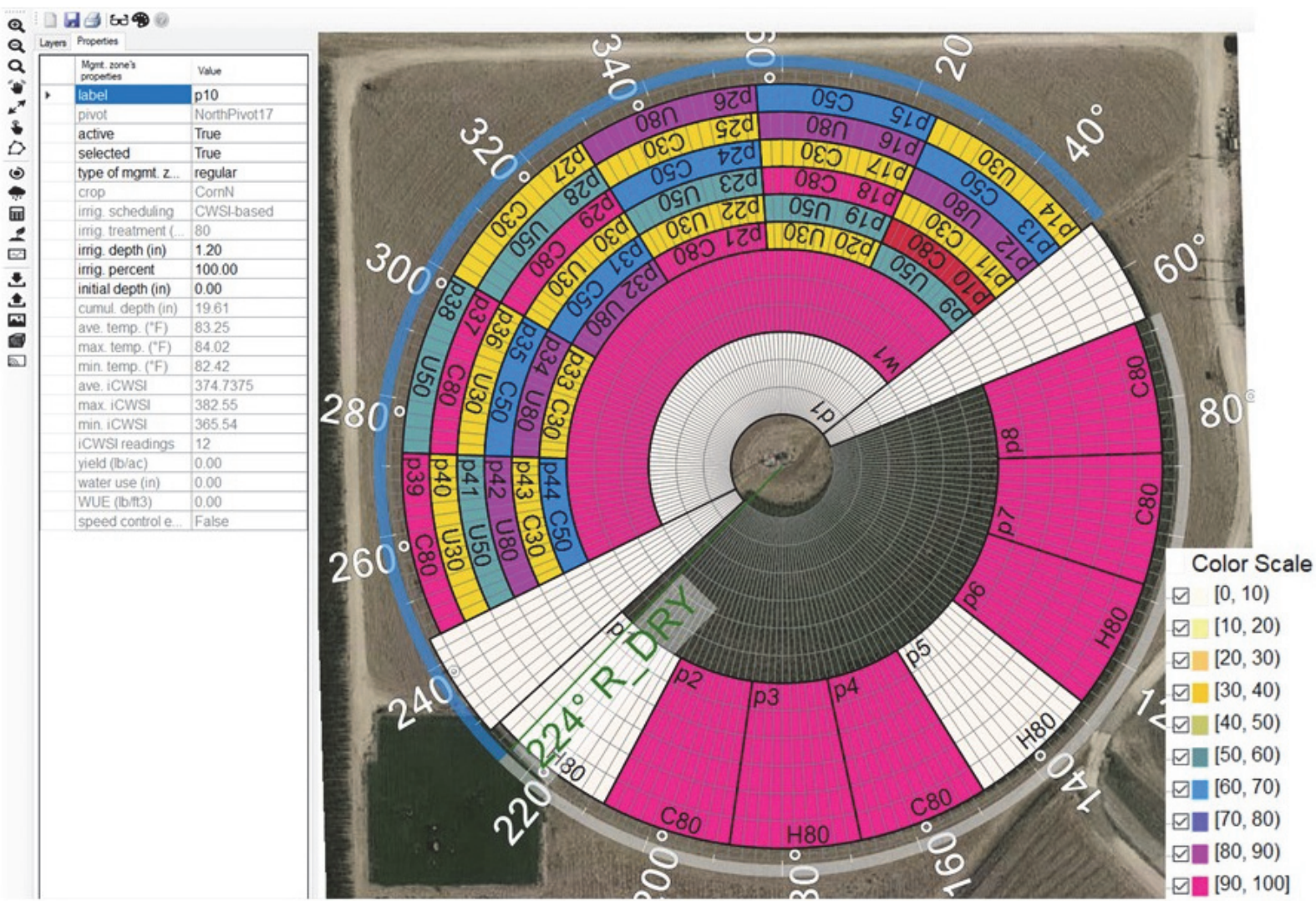

Figure 8. Site-specific prescription map generated on July 8, 2017, for the experimental setup in figure 6. Recommended prescriptions assigned to MZs (experimental plots) are shown as percentages of a pre-specified maximum irrigation depth of $30.5 \mathrm{~mm}(1.2$ in.). The interiors of MZs are colored according to those percentages, following the color scale shown in the bottom right corner. Recommended prescriptions can be easily modified by selecting an MZ (p10 in this figure) and then changing its irrigation depth or irrigation percent in the table of properties shown at the left of the main panel. A concentric progress bar indicates the area covered by the lateral pipeline during an irrigation event. The color of the progress bar changes from light gray to blue as the center pivot advances counterclockwise from an angle of $\sim 50^{\circ}$ to an angle of $210^{\circ}$. The color of the line indicating the position of the lateral pipeline is green to indicate that the center pivot is running dry because it is inside an angular sector with no irrigation.

to their recommended prescriptions (watering rates), presented as percentages of a pre-specified maximum irrigation depth of $30.5 \mathrm{~mm}$ (calculated by considering that the center pivot could run across the field approximately three times in a 7-day period, and multiplying three times the peak daily water use for corn in this region in $\mathrm{mm}$ ).

The prescription of an $\mathrm{MZ}$ can be easily modified by the user after selecting an $\mathrm{MZ}$ and overriding its irrigation depth or irrigation percent in the table of properties displayed to the left of the main panel (fig. 8). The color used to draw the interior of an $\mathrm{MZ}$ whose prescription has been changed will be automatically updated to reflect the change. Tables with properties of MZs provide additional valuable information, such as basic statistical indicators of canopy temperatures and $\mathrm{iCWSI}_{x}$ values within the MZ (fig. 8). Similarly, tables with pertinent properties of a soil water or plant sensor (TDR or IRT, respectively) are displayed when selected by the user.

After a prescription map has been inspected, it can be submitted to a Pro2 control panel using the irrigation toolbox form incorporated in the server. This form also allows users to start an irrigation event after submitting the prescription map. After the map is uploaded to the control panel, users can select the positions (angles) where the center pivot will start and stop the event, as well as the direction of the center pivot's movement during the event. If the starting position is different from the current position of the center pivot, the client sends commands to the control panel to start moving the center pivot dry in whichever direction the starting position can be reached in the shortest time. Once the center pivot arrives at the starting position, the client sends new commands to turn the water on and, if needed, adjusts the direction to match the user's instructions. The client periodically monitors the irrigation event and, if needed, sends commands to the control panel to ensure that irrigation amounts specified in a prescription map are applied as intended.

The server incorporates graphical tools to monitor the status of center pivots, as well as the status of an irrigation event. The position of a center pivot is displayed in the main panel as a line representing its lateral pipeline that rotates as the center pivot traverses the field. The color of this line changes from red when the center pivot is stopped (fig. 6) to green when it is running dry (fig. 8) and then to blue when it is running wet. The status of an irrigation event can be monitored at a glance in the main panel with a concentric progress bar drawn near the outer perimeter of the scaled representation of the field (fig. 8). The progress bar is spread over the area to be covered during the event, and its color changes from light gray to blue as the center pivot advances so that 


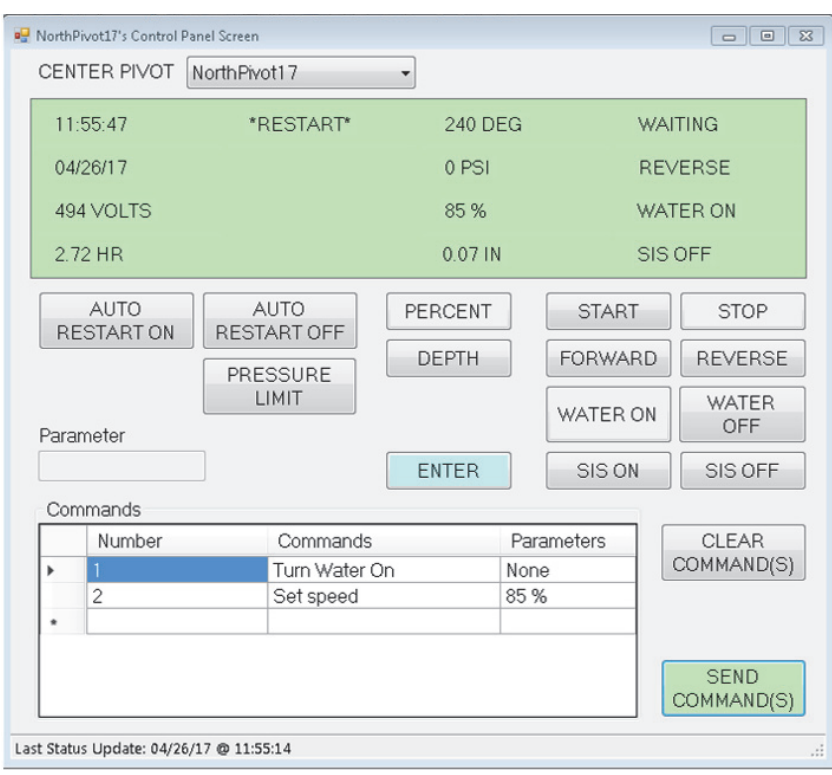

Figure 9. Control panel screen that allows users to remotely supervise and operate a VRI center pivot through the submission of a set of control commands to a Pro2 panel. Values are in customary units for U.S. end users.

the blue portion of the progress bar highlights the area that has been irrigated and the light gray portion highlights the area that remains to be irrigated (fig. 8).

The server implements additional software tools to assist in the operation of an ISSCADA-VRI center pivot system. Among these tools is a control panel screen that emulates the user interface of a Pro2 control panel. This screen was built to facilitate the adoption of the ARSPivot software by users familiar with the Pro2 control panel (fig. 9). This screen allows the user to remotely supervise and control a center pivot by sending a set of commands to a Pro2 panel. Each command can be entered by clicking its respective button and then indicating its parameter (if applicable). The command is then included in a table where the user can visualize the set of commands entered before they are submitted to a Pro2 panel. The screen ensures manual control of the center pivot if necessary.

\section{CONCLUSiOnS}

A software package, named ARSPivot, was developed to supervise and operate a complex system comprised of a center pivot VRI system and an embedded Irrigation Scheduling Supervisory Control and Data Acquisition (ISSCADA) system automatically interfacing with soil water, plant, and microclimate sensing systems supporting site-specific irrigation scheduling methods based on plant stress and soil water content data. The software package consists of two programs running independently but interacting through a clientserver architecture. The client is entrusted with maintaining continuous communication with sensing systems and a Pro2 control panel. The server provides users with a friendly GUI that facilitates operation of the network of sensing systems, irrigation scheduling methods, and VRI machinery. The server also assists the process of setting up a coupled ISSCADA VRI center pivot system through multiple data entry forms and implements multiple decision support tools to improve irrigation management with VRI center pivot systems. The server was developed as a flexible program capable of managing any arrangement of irrigation management zones under both VRI zone control and VRI speed (sector) control. ARSPivot has also enabled researchers at multiple ARS locations (Bushland, Tex., Florence, S.C., Portageville, Mo., and Stoneville, Miss.) to test the performance of the ISSCADA system under different climates and field conditions.

\section{ACKNOWLEDGeMENTS}

This material is based upon work that is supported by the USDA National Institute of Food and Agriculture under Award No. 2016-67021-24420. The work reported in this article was also accomplished as part of a Cooperative Research and Development agreement between USDA-ARS and Valmont Industries, Inc., Valley, Nebraska (Agreement No. 58-3K95-0-1455-M) and with funds from the Ogallala Aquifer Program.

\section{REFERENCES}

AgSense. (2019). Weather: AgSense applications. Huron, SD: AgSense. Retrieved from http://www.agsense.com/applications/weather

Andales, A. A., Bauder, T. A., \& Arabi, M. (2014). A mobile irrigation water management system using a collaborative GIS and weather station networks. Adv. Agric. Syst. Model.(5), 284289. https://doi.org/10.2134/advagricsystmodel5.c3

Andrade, M. A., O'Shaughnessy, S. A., \& Evett, S. R. (2015). ARSmartPivot v.1: Sensor based management software for center pivot irrigation systems. ASABE Paper No. 152188736. St. Joseph, MI: ASABE. https://doi.org/10.13031/aim.20152188736

Andrade, M. A., O'Shaughnessy, S. A., \& Evett, S. R. (2017). ARSPivot, A sensor-based decision support tool for the integrated irrigation management of VRI center pivot systems. Proc. 29th Annual Central Plains Irrigation Conf. Colby, KS: Central Plains Irrigation Association. Retrieved from https://www.ksre.k-state.edu/irrigate/oow/p17/Andrade17.pdf

Andrade, M. A., O'Shaughnessy, S. A., \& Evett, S. R. (2020). ARSPivot, A sensor-based decision support software for variable-rate irrigation center pivot systems: Part B: Application. Trans. ASABE, 63(5), https://doi.org/10.13031/trans.13908, in press.

Colaizzi, P. D., O’Shaughnessy, S. A., \& Evett, S. R. (2018). Calibration and tests of commercial wireless infrared thermometers. Appl. Eng. Agric., 34(4), 647-658. https://doi.org/10.13031/aea.12577

Evans, R. G., Iversen, W. M., \& Kim, Y. (2012). Integrated decision support, sensor networks, and adaptive control for wireless site-specific sprinkler irrigation. Appl. Eng. Agric., 28(3), 377-387. https://doi.org/10.13031/2013.41480

Evans, R. G., LaRue, J., Stone, K. C., \& King, B. A. (2013). Adoption of site-specific variable-rate sprinkler irrigation systems. Irrig. Sci., 31(4), 871-887. https://doi.org/10.1007/s00271-012-0365-x

Evett, S. R., O’Shaughnessy, S. A., \& Peters, R. T. (2014). Irrigation scheduling and supervisory control and data acquisition system for moving and static irrigation systems. U.S. Patent No. 8,924,031 B1. 
Evett, S. R., O’Shaughnessy, S. A., Andrade, M. A., Colaizzi, P. D., Schwartz, R. C., Schomberg, H. S., ... Sui, R. (2020). Theory and development of a VRI decision support system: The USDAARS ISSCADA approach. Trans. ASABE, 63(5), https://doi.org/10.13031/trans.13922, in press.

Google. (2019). Google maps platform static API. Retrieved from https://developers.google.com/maps/documentation/mapsstatic/intro

Hager, J. W., Behensky, J. F., \& Drew, B. W. (1989). The universal grids: Universal transverse mercator (UTM) and universal polar stereographic (UPS) (1st ed.). Washington, DC: Defense Mapping Agency.

Jackson, R. D., Idso, S. B., Reginato, R. J., \& Pinter Jr., P. J. (1981). Canopy temperature as a crop water stress indicator. Water Resour. Res., 17(4), 1133-1138. https://doi.org/10.1029/WR017i004p01133

King, B. A., Wall, R. W., \& Wall, L. R. (2005). Distributed control and data acquisition system for closed-loop site-specific irrigation management with center pivots. Appl. Eng. Agric., 21(5), 871-878. https://doi.org/10.13031/2013.19715

Kranz, W. L., Evans, R. G., Lamm, F. R., O’Shaughnessy, S. A., \& Peters, R. T. (2012). A review of mechanical move sprinkler irrigation control and automation technologies. Appl. Eng. Agric., 28(3), 389-397. https://doi.org/10.13031/2013.41494

Leib, B. G., Elliott, T. V., \& Matthews, G. (2001). WISE: A weblinked and producer oriented program for irrigation scheduling. Comput. Electron. Agric., 33(1), 1-6. https://doi.org/10.1016/S0168-1699(01)00170-3

Liakos, V., Porter, W., Liang, X., Tucker, M. A., McLendon, A., \& Vellidis, G. (2017). Dynamic variable-rate irrigation: A tool for greatly improving water use efficiency. Adv. Animal Biosci., 8(2), 557-563. https://doi.org/10.1017/S2040470017000711

Microsoft. (2019). Microsoft remote desktop. Retrieved from https://www.microsoft.com/en-us/p/microsoft-remotedesktop/9wzdncrfj3ps?activetab=pivot:overviewtab

Microsoft. (2020). Socket class. Retrieved from https://docs.microsoft.com/enus/dotnet/api/system.net.sockets.socket?view=netcore-3.1

Navarro-Hellín, H., Martínez-del-Rincon, J., Domingo-Miguel, R., Soto-Valles, F., \& Torres-Sánchez, R. (2016). A decision support system for managing irrigation in agriculture. Comput. Electron. Agric., 124, 121-131. https://doi.org/10.1016/j.compag.2016.04.003

O'Shaughnessy, S. A., \& Evett, S. R. (2010). Canopy temperature based system effectively schedules and controls center pivot irrigation of cotton. Agric. Water Mgmt., 97(9), 1310-1316. https://doi.org/10.1016/j.agwat.2010.03.012

O'Shaughnessy, S. A., Andrade, M. A., \& Evett, S. R. (2017). Using an integrated crop water stress index for irrigation scheduling of two corn hybrids in a semi-arid region. Irrig. Sci. 35(5), 451-467. https://doi.org/10.1007/s00271-017-0552-x

O’Shaughnessy, S. A., Andrade, M. A., Stone, K. C., Vories, E. D., Sui, R., \& Evett, S. R. (2018). Adapting a VRI irrigation scheduling system for different climates. Proc. Irrigation Tech. Conf. Fairfax, VA: Irrigation Association. Retrieved from https://www.irrigation.org/IA/FileUploads/IA/Resources/Techni calPapers/2018/Adapting_SiteSpecific_Irrigation_OSHAUGHNESSY.pdf

O’Shaughnessy, S. A., Evett, S. R., \& Colaizzi, P. D. (2015). Dynamic prescription maps for site-specific variable-rate irrigation of cotton. Agric. Water Mgmt., 159, 123-138. https://doi.org/10.1016/j.agwat.2015.06.001

O’Shaughnessy, S. A., Evett, S. R., Colaizzi, P. D., \& Howell, T. A. (2012). A crop water stress index and time threshold for automatic irrigation scheduling of grain sorghum. Agric. Water Mgmt., 107, 122-132.

https://doi.org/10.1016/j.agwat.2012.01.018

O’Shaughnessy, S. A., Evett, S. R., Colaizzi, P. D., \& Howell, T. A. (2013). Wireless sensor network effectively controls center pivot irrigation of sorghum. Appl. Eng. Agric., 29(6), 853-864. https://doi.org/10.13031/aea.29.9921

O’Shaughnessy, S. A., Evett, S. R., Colaizzi, P. D., Andrade, M. A., Marek, T. H., Heeren, D. M., ... LaRue, J. L. (2019). Identifying advantages and disadvantages of variable-rate irrigation: An updated review. Appl. Eng. Agric., 35(6), 837-852. https://doi.org/10.13031/aea.13128

O’Shaughnessy, S. A., Hebel, M. A., Evett, S. R., \& Colaizzi, P. D. (2011). Evaluation of a wireless infrared thermometer with a narrow field of view. Comput. Electron. Agric., 76(1), 59-68. https://doi.org/10.1016/j.compag.2010.12.017

Oswald, J. K. (2006). Automated water management for center pivot irrigation. MS thesis. Brookings, SD: South Dakota State University, Agricultural and Biosystems Engineering.

Peters, R. T., \& Evett, S. R. (2004). Modeling diurnal canopy temperature dynamics using one-time-of-day measurements and a reference temperature curve. Agron. J., 96(6), 1553-1561. https://doi.org/10.2134/agronj2004.1553

Peters, R. T., \& Evett, S. R. (2008). Automation of a center pivot using the temperature-time-threshold method of irrigation scheduling. J. Irrig. Drain. Eng., 134(3), 286-291. https://doi.org/10.1061/(ASCE)0733-9437(2008)134:3(286)

Prajamwong, S., Merkley, G. P., \& Allen, R. G. (1997). Decision support model for irrigation water management. J. Irrig. Drain. Eng., 123(2), 106-113. https://doi.org/10.1061/(ASCE)07339437(1997)123:2(106)

Schwartz, R. C., Evett, S. R., Anderson, S. K., \& Anderson, D. J. (2016). Evaluation of a direct-coupled time-domain reflectometry for determination of soil water content and bulk electrical conductivity. Vadose Zone J., 15(1), 2016. https://doi.org/10.2136/vzj2015.08.0115

Singels, A., Kennedy, A., \& Bezuidenhout, C. (1998). Irricane: A simple computerised irrigation scheduling method for sugarcane. Proc. South African Sugar Tech. Assoc., 1, 1-6.

Stone, K., Bauer, P., O’Shaughnessy, S., Andrade, M., \& Evett, S. (2019). A variable-rate irrigation decision support system for corn in the U.S. Eastern Coastal Plain. In J. V. Stafford (Ed.), Proc. 12th European Conf. on Precision Agriculture (pp. 673679). Wageningen, The Netherlands: Wageningen Academic. https://doi.org/10.3920/978-90-8686-888-9_83

Thysen, I., \& Detlefsen, N. K. (2006). Online decision support for irrigation for farmers. Agric. Water Mgmt., 86(3), 269-276. https://doi.org/10.1016/j.agwat.2006.05.016

USDA-NRCS. (2019). Web soil survey. Washington, DC: USDA Natural Resources Conservation Service. Retrieved from http://websoilsurvey.nrcs.usda.gov/

Vories, E., O'Shaughnessy, S., \& Andrade, M. (2019). Comparison of precision and conventional irrigation management of cotton. In J. V. Stafford (Ed.), Proc. 12th European Conf. on Precision Agriculture (pp. 695-702). Wageningen, The Netherlands: Wageningen Academic. https://doi.org/10.3920/978-90-8686888-9_86 